\title{
Reducing barriers to accessing fistula repair: Establishing a baseline in Katsina
}

Population Council

Follow this and additional works at: https://knowledgecommons.popcouncil.org/departments_sbsr-rh

Part of the Demography, Population, and Ecology Commons, Family, Life Course, and Society Commons, International Public Health Commons, Maternal and Child Health Commons, and the Women's Health Commons How does access to this work benefit you? Let us know!

\section{Recommended Citation}

"Reducing barriers to accessing fistula repair: Establishing a baseline in Katsina," brief. Washington, DC: Population Council, 2017. 


\section{REDUCING BARRIERS TO ACCESSING FISTULA REPAIR: ESTABLISHING A BASELINE IN KATSINA}

\section{BACKGROUND}

Obstetric fistula (OF) is preventable and surgically treatable, but women who lack access to quality maternal healthcare often live with OF for many years. For every 1,000 births, it has been estimated that 2.11 women develop fistula in Nigeria ${ }^{1}$ and despite the establishment of national fistula centers across Nigeria, the majority of women with OF remain unrepaired.

As a partner on the Fistula Care Plus (FC+) project, the Population Council is conducting implementation research that tests solutions to treatment barriers. Formative research in Nigeria's Katsina State found that a lack of knowledge among lower level providers and women and families of how the condition occurs, where treatment is available, and the signs and symptoms of OF, as well as transportation costs, affect women's access to screening and repair.

\section{IMPLEMENTATION RESEARCH}

The research aim is to understand whether a comprehensive information, screening, and referral intervention can reduce transportation, communications, and financial barriers to accessing preventive care, detection, and treatment of fistula in Katsina State.

The intervention model follows a "3-1-1" pattern:

- Three channels for fistula messages and screening so women can learn about their fistula status:

- Mass media and interactive voice response (mobile phones)

- Community outreach agents

- Primary health care workers

- One screening algorithm for detecting fistula condition

- One enabler: transport voucher for suspected fistula cases to the fistula repair center.

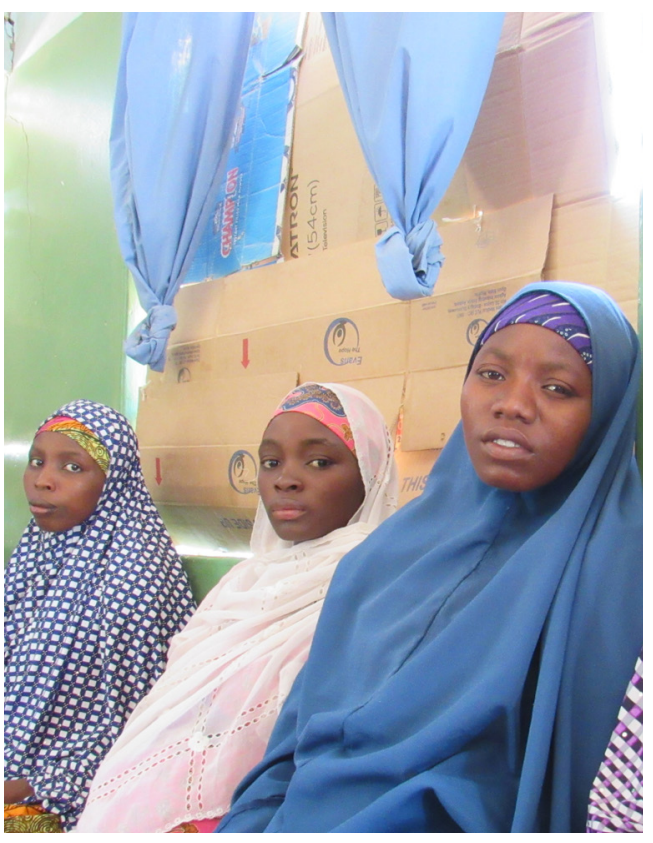

USAID

Fistula Care Plus

\footnotetext{
${ }^{1}$ Ijaiya MA, Rahman AG, Aboyeji AP, Olatinwo AW, Esuga SA, Ogah OK, Raji HO, Adebara IO, Akintobi AO, Adeniran AS,
}

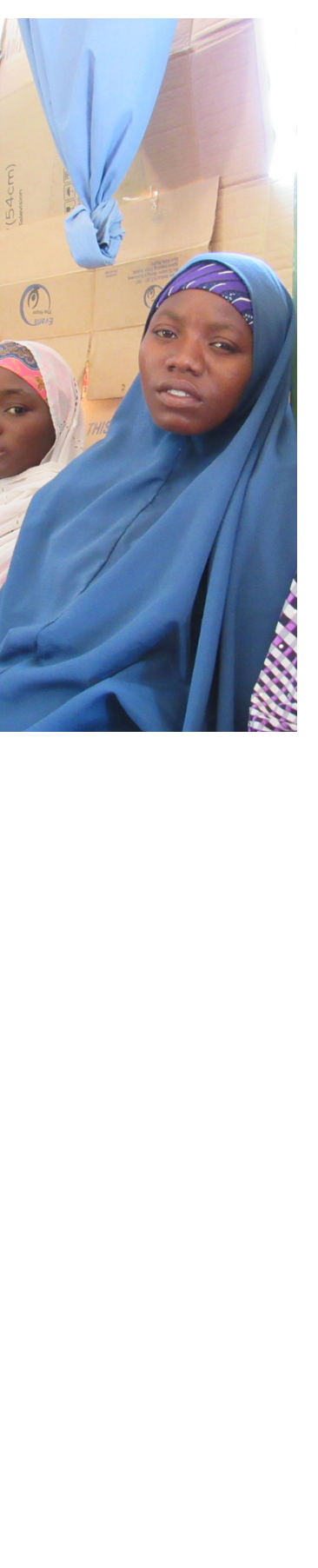

The Population Council conducts research and delivers solutions that improve lives around the world. Big ideas supported by evidence:

It's our model for global change. popcouncil.org

(C) 2017 The Population Council, Inc. COUNCIL

EngenderHealth

Ideas. Evidence. Impact.
POPULATION 


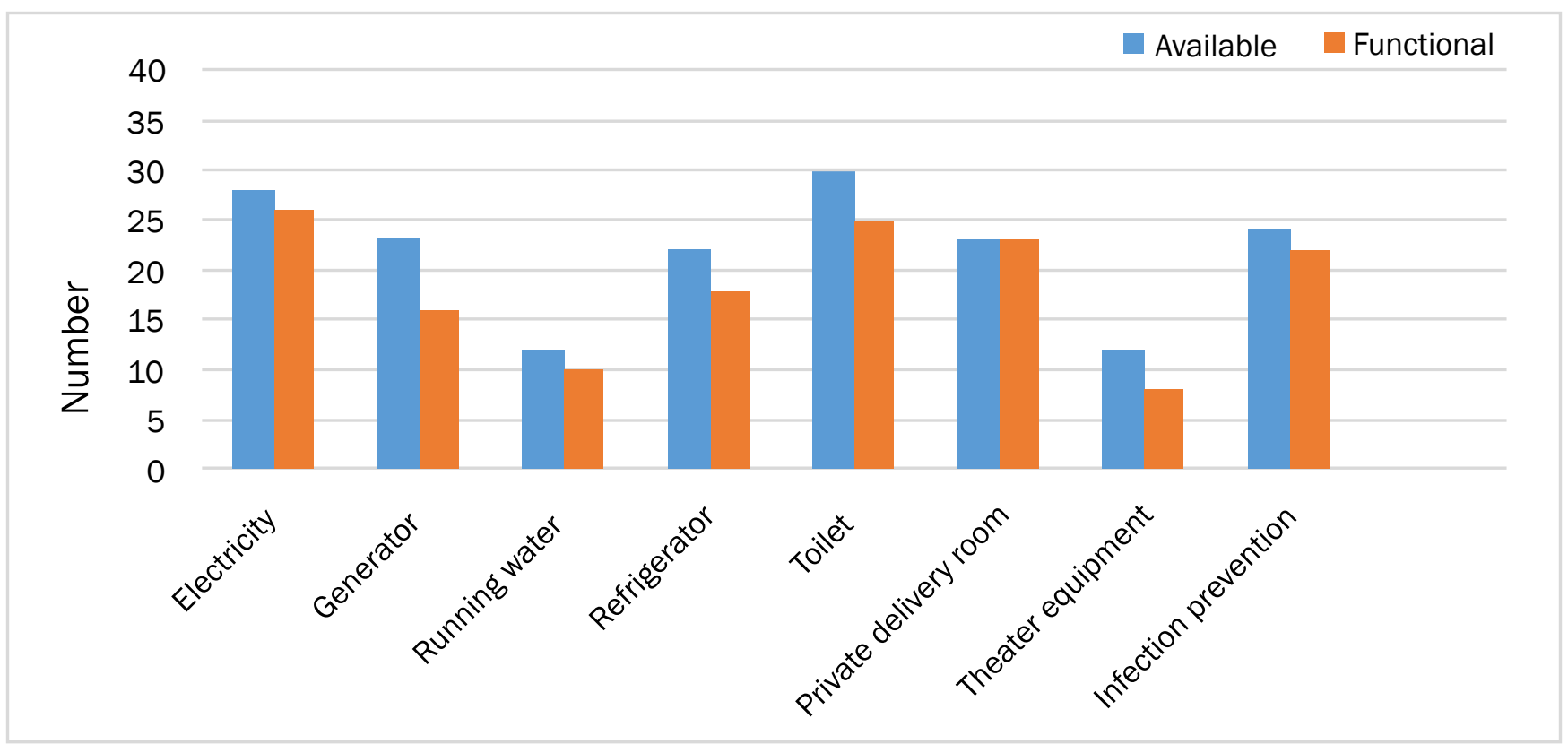

\section{BASELINE DATA COLLECTION}

In Katsina, Population Council collected baseline data from both intervention and comparison local government areas (LGAs). Researchers conducted 37 facility assessments of primary health centers (PHCs) and one facility assessment of the fistula center to assess health systems capacity; 88 PHC provider surveys that assessed their knowledge, attitudes, and perceptions of barriers, and operational challenges that influence how women access care for fistula; and 81 surveys with women who had received fistula repair about the barriers and enablers they experienced. A subset of 30 post-repair women interviews and four focus group discussions held separately with men and women residing in selected communities - also further explored barriers and enablers to accessing care. All tools covered transport and referral barriers, as well as psycho-social, cultural, facility shortages, awareness of service options, quality of care, social, political, and financial barriers to accessing care.

\section{BASELINE FINDINGS}

Facility Assessment. Except for three privately-owned facilities, all PHC facilities are publicly owned. There are few doctors among the staff at facilities; most providers are nurse/midwives or CHEWs. Facility representatives report varied infrastructural capacity across the overall sample (Figure 1). Poor referral mechanisms exist at
PHCs for suspected fistula cases. For instance, only about $32.4 \%$ have ambulances available; $27 \%$ of transport arrangements are made by the fistula patient or her relatives.

PHC Providers. PHC providers - predominately community health extension workers - have limited knowledge of prevention and treatment of fistula. Only 19-26\% of providers spontaneously mentioned prolonged and obstructed labor as labor and delivery complications, and less than $7 \%$ correctly identified leaking urine/feces or foul-smelling discharge as postnatal danger signs. About $36.4 \%$ of the providers reported having seen prolonged or obstructed labor among their clients. Though no referrals were captured across the 37 PHC facility assessments, $17 \%$ of providers report referring women with fistula to repair centers. Of those, out of which only $26.7 \%$ counselled the referred client. This counseling rate is less than the already low proportion of providers who know that OF clients should be counseled and referred (15.9\%).

Providers understand some of the barriers women face when trying to access fistula repair. In Katsina State, the three most frequently mentioned barriers by the 88 surveyed providers were 1) Shame of having OF (85.2\%), 2) Depression and anxiety (40.9\%), and 3) Feeling unclean (34.1\%). 
TABLE 1. Fistula repair client survey in Katsina $(n=81)$

\begin{tabular}{|l|l|}
\hline Fistula experience indicator & Frequency (\%) \\
\hline Women began leaking post-delivery & $80(98.8)$ \\
\hline OF cases following normal delivery & $33(40.0)$ \\
\hline Average amount of time clients live with fistula (of any sort) & Mean: 1.7 years; Range: $1-5$ \\
\hline Average number of attempts to seek fistula treatment & Mean: 1.8 times; Range: $1-3$ \\
\hline Women who previously sought fistula treatment & $39(48.1)$ \\
\hline
\end{tabular}

Fistula repair clients. Of the 81 women surveyed postrepair, 54\% were between 15 and 29 years of age, $86.4 \%$ married, and all Muslim. Only $14.8 \%$ had any formal public education, $48.1 \%$ attended Quranic school, and less than $10 \%$ ever worked for an income. Table 1 shows that on average, women live with fistula for 1.7 years, though some live with the condition for up to five years. $48.1 \%$ previously sought treatment for their fistula -on average, these women have sought both formal and traditional care at least twice.

Barriers. The stigma and shame associated with uncontrollably leaking in public leads to psychological barriers to care-seeking for some women. Findings show that nearly $52 \%$ of women were embarrassed and $56 \%$ felt isolated because of their condition. They also reported social barriers, such as not having someone to support them in reaching/seeking repair sites (24.7\%) - this provides insight into the cultural and gender dynamics around family and intimate partner roles. Women lack knowledge that fistula is a condition that can be treated (28.4\%) and do not know where to go for fistula repair (50.6\%).

Despite free elements of fistula operations in Nigeria, the transport cost and perceived costs constrains access to repair in Katsina. Abandoned women and those living with spouses and families experience financial strain because competing costs in resource-poor households often deter or delay access to transport to/from repair centers. Our sample shows that, many women felt they do not have money to pay for the needed medical care (64.2\%) and felt the cost of transportation to repair sites and accommodation was too high (45.7\%).

Other barriers included fear of pain/discomfort during travel to facilities $(22.2 \%)$ and of bad treatment by providers at the fistula center (17.4\%). Some women had been told by providers that their fistula would heal itself (13.5\%), while others had been told by providers in the past that their fistula was untreatable (18.8\%).
Enablers. Enablers of accessing the fistula center are complex, but center around effective media advertising of fistula centers, timely referral by PHC providers, and the social support women have from their families particularly male relatives in increasing awareness around fistula and facilitating transport to the facility.

"I got the information from my elder brother while we were going to school...Almost all my family members were here - they helped me... [I was referred] from a [secondary] Hospital, seeing my condition they [providers] referred us... I was given a letter of referral... we used KTSTA and then on reaching Katsina we used keke napep [tricycle] to the centre...My elder brother paid everything." (IDI, repaired woman, 16 years)

When women considered delaying care seeking due to the perceived high cost of treatment that may have led them to traditional medicine, free repair services at the fistula centers restored hope and confidence in the women.

"This [fistula center] is where you will get it free and the others [facilities] you have to pay, there is difference now. Honestly, I even stayed for almost 20 months in the hospital ... until I fully recovered, you know there are rules one has to stay for six months or five." (IDI, repaired woman, 17 years)

\section{CONCLUSION}

Baseline data reveal the necessity of a comprehensive intervention to address fistula treatment barriers in Katsina. Not only do PHC providers lack adequate knowledge of fistula, referral and counseling, but women and community members report that access barriers to fistula centers bring persistent logistical, financial, awareness, and social challenges. These findings inform the intervention, which builds on existing enablers in Katsina, such as media communication and transport/ social support, and aims to promote greater access to fistula repair in the state. 